\title{
Improved Huff Model for Estimating Urban Rail Transit Station Catchment Areas considering Station Choices
}

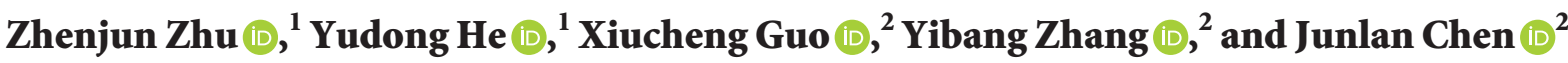 \\ ${ }^{1}$ College of Automobile and Traffic Engineering, Nanjing Forestry University, No. 159 Longpan Road, Nanjing 210037, China \\ ${ }^{2}$ School of Transportation, Southeast University, No. 2 Dongnandaxue Road, Nanjing 211189, China \\ Correspondence should be addressed to Junlan Chen; 220183011@seu.edu.cn
}

Received 14 November 2019; Revised 19 February 2021; Accepted 23 February 2021; Published 9 March 2021

Academic Editor: Antonio Comi

Copyright (C) 2021 Zhenjun Zhu et al. This is an open access article distributed under the Creative Commons Attribution License, which permits unrestricted use, distribution, and reproduction in any medium, provided the original work is properly cited.

Estimating urban rail transit station catchment areas is of great significance to deepening our understanding of Transit-Oriented Development in Chinese megacities. This study investigated station choices of residents and considered that residents may not only pay attention to the proximity to stations when the URT system develops into a relatively mature network. An improved Huff model was proposed to calculate the probability of residents' station choice, which considered the station attractiveness. The station attractiveness is measured by three variables: walk score, public transport accessibility level, and service and facility index. The additive form based on multicriteria decision is adopted to incorporate experts' opinions on the importance of three variables. In this study, extended catchment areas that can be accessed by cycling and feeder bus services are adopted to replace the conventional pedestrian-oriented catchment areas. A case study of Xi'an, China, was used to validate the applicability of the proposed methodology. The results revealed that the methodology effectively solved the problem. The findings could be used as a reference and provide technical support to policymakers and city planners with regard to the transport facilities configuration for URT station catchment areas, which contributes to facilitating transit-oriented development.

\section{Introduction}

Urban rail transit systems are especially favored by planners because of their potential to attract car users [1]. Regarded as sustainable public transportation modes to ease urban traffic congestion and energy consumption, reduce the environmental effects of transportation, and promote economic growth [2], URT systems are becoming increasingly popular worldwide for urban and suburban areas, and a growing number of cities have built or approved URT systems [3]. Currently, more than a hundred URT systems successfully operate in the United States, Europe, Canada, South America, and Asia [4]. Following land, environmental, and energy conservation policies in China, land developments show a high density and intensive characteristics, and more rail transit systems are needed to guide the optimization of urban spatial structure in Chinese megacities. Beijing, Shanghai, Guangzhou, Shenzhen, and so on have gradually formed multimodal and integrated public transportation systems within URT as the backbone transport mode. To the end of 2019, 210 URT lines and $6386.9 \mathrm{~km}$ mileages were in operations, which suggests that URT in China has entered into a period of rapid development [5].

URT stations are the points of access to a transportation system and the ability to access them conveniently and quickly affects property values [6]. The construction experience of URT in various countries in the world shows that the impact of URT on the urban spatial structure is mainly reflected in URT station catchment areas, and the land use will in turn provide sufficient passenger flow for URT. In the context of this study, a URT station catchment area refers to the area extent to which the majority of users will typically be found. Catchment areas around URT stations offer ideal conditions for Transit-Oriented Development (TOD), which are also a prerequisite for the calculation of several fundamental statistical including latent demand, market share, accessibility, and stop spacing [7]. Also, residents living in URT station catchment areas had higher neighborhood satisfaction and experienced a greater perception of safety while walking [8]. Moreover, studies have shown that retail, 
office, and residential rents, as well as housing prices, are higher in more walkable locations [9], suggesting that URT's contribution to making a place more walkable can result in increased economic activity and property tax revenue. Therefore, estimating URT catchment areas is a significant issue, which will help to deepen our understanding of TODs in Chinese megacities.

This study aims to estimate UTR station catchment areas using a new methodology based on the improved Huff model in Chinese megacities. From the view of conventional pedestrian-oriented and transit-oriented planning, this study focuses on the walk score, public transport accessibility level, and service and facility index, when it comes to the station attractiveness. The remainder of this study is organized as follows. Section 2 contains a literature review. Section 3 describes the methodology. Section 4 details a case study. Conclusions are presented in Section 5.

\section{Literature Review}

Numerous methods have been proposed to estimate catchment areas that range greatly in sophistication, and the choice between them largely depends on the complexity of the competitive forces involved, along with their computational complexity and data availability. Regarding proximity-only models, they have shown that buffer rings and polygons depict drive time along with a network from a point of interest. Assuming that the distance from the origin to destination is Euclidean and omnidirectional, buffer rings are perhaps the simplest method to calculate. However, factors such as street layout, land use, parking capacity, transit service, location of rail transit stations, and multimodal accessibility also have an impact on the size of catchment areas [10-12]. Moreover, the existing approaches make generalized and strictly binary decisions about maximum buffer distance [13]. For example, $800 \mathrm{~m}$ has been broadly accepted as a reasonable walking distance to a rail transit station [14-16]. What is more, employment in the $800 \mathrm{~m}$ station area, service level, bus connectivity, station location in the Central Business District (CBD), distance to the nearest station, and terminal are all important factors affecting passenger flow [17]. However, some scholars considered that this distance varies spatially, with people living in suburbs likely to accept larger distances [18] and longer travel times [19] than people living in the CBD. Service areas are the more realistic way of delineating catchment areas and valid where users are expected to use the closest facilities [20]. Scholars used distance decay to indicate distances in terms of the proportion of users who will walk less than a certain threshold, while the variation also exists due to the data availability and locations. However, like buffer rings, they can be poor predictors of catchment areas where proximity is not the only consideration for selecting a particular service. Other factors such as user preferences and traffic supply can also affect people's choices [21-24]. The Huff model shows its unique advantages in this respect. The Huff model predicts the influence of the business circle by the attractiveness of different stores [25]. This is analogous to the method used to measure the extent of the urban rail transit station catchment areas. Lin et al. introduced the Huff model to deal with the problem of facility configuration around rail stations [26].

One of the earliest studies regarding URT station choice models was developed by Kastrenakes [27] for predicting railway travel in the New Jersey area. The most common approaches include the discrete choice model, logistic regression model, multinomial logit model, cross-nested logit model, and nested logit model [11, 28, 29]. Residents will not necessarily choose a URT station only due to the proximity to the residence. Some researchers have found that the distance was not the only factor affecting rail transit station choice; there are also many factors that affect their choices, such as total travel time, access time, cost, service quality, service frequency, facilities available at the station, carriage crowding, parking search time, demographics, and safety [30-33]. For instance, some residents may choose a rail station nearer to their destinations for saving costs; others may choose a rail transit station further from their destinations for securing a seat. Using the survey data from the Dutch railway, Debrezion et al. [34] found that only $47 \%$ of the passengers choose their nearest station. Birgillito et al. used the stochastic utility model to study the main variables that affect passenger choice and their relative weights in discontinuous spaces [35]. This study does illustrate that the boundary of station catchment areas also depends on the access to facilities and services at stations. As such, gravity models may be more appropriate as they include not only distance but also attractiveness in their computation.

Although scholars have proposed numerous methods to estimate catchment areas, there are still some research gaps. First, most previous studies on estimating catchment areas have been conducted in developed countries. As we know, there is a big difference in urban built environments between developed and developing countries; in particular, many developing countries are still in a stage of rapid urbanization with the concurrent rapid development of urban transportation. Particularly in China, the traffic problem is becoming increasingly serious [36]. Second, studies regarding station choices mainly concentrated on the railway; while the characteristics of URT are different from the railway, station choices may be also different. Third, the existing methods concern more about the proximity to stations, while they rarely include stations' attractiveness in their computation, which may be partly due to the fact that residents may have more travel choices when the URT system develops into a relatively mature network. Fourth, the major access mode is considered as walking in the conventional TOD framework; however, to improve the effectiveness of TOD, the integration of cycling and feeder bus can be regarded as good alternatives; thus, URT station catchment areas can be increased.

To fill these knowledge gaps, this study used a new methodology based on the improved Huff model for understanding and determining URT station catchment areas in Xi'an, China. This study aims to fill the research gap in the estimation of URT catchment areas. 


\section{Methodology}

3.1. Improved Huff Model. One of the most enduring catchment area models was developed by Huff [25], a probabilistic gravity model originally applied to forecast customer behavior among competing retail stores using three main variables: distance, attractiveness, and competition [37]. Its major advantage over other simplistic retail models is the ability to simultaneously estimate a customer's patronage probability for many centers [38], including those with overlapping trade areas. The Huff model facilitates analytical decisions based on multiple choices and has been applied in other research areas. These areas include the accessibility of healthcare and food services or the choice of different entertainment venues. This study uses the improved Huff model for application to the choice of URT stations. The probability $\left(P_{i j}\right)$ that a resident located at origin community $i$ would choose to travel at a URT station $j$ is calculated as follows:

$$
P_{i j}=\frac{A_{j}^{\lambda} \cdot T_{i j}^{-\beta}}{\sum_{j=1}^{n} A_{j}^{\lambda} \cdot T_{i j}^{-\beta}} .
$$

3.2. Parameter Calibration. Parameter calibration is critical for model application; this study proposes the following calibration methods for model parameters.

$\lambda$ is an attractiveness parameter estimated from empirical observations. In essence, this enables the modeling of nonlinear behavior of the attractiveness parameter, and within the Huff model, it can be applied to account for various qualitative factors such as the ease of access to a particular rail transit station and perception of attractiveness (normally estimated from empirical observations). However, it was not possible to account for these effects universally, and as such, our model only considers the effect of accessibility on the extent of potential catchments. For all other distances, a default value equal to 1 was used. Birkin et al. [39] considered the attractiveness parameter $\lambda$ of residence-based travel as a value of 1 . As such, this study assumes that "ease of access" is proxied by a $10 \mathrm{~min}$ walking, cycling, and feeder bus services between the residents' origin and a UTR station and increases the perceived attractiveness of a given center twofold.

$\beta$ is the distance decay parameter and usually takes a value of 1 and 2 [20], depending on factors such as the type of retail center or competition. Dramowicz [37] also found the distance decay parameter as a value of 2 . Modeling the relationship between distance and the percentage of URT trips in the Matlab ${ }^{\mathrm{TM}}, \beta$ is estimated to be 1.93 . Based on existing studies and our model, this study adopted $\beta=2$.

$T_{i j}$ is the travel time from an origin community $i$ to the city center through a URT station $j$. Considering the city center, $T_{i j}$ includes two aspects, which can be calculated as follows:

$$
T_{i j}=T_{i j \text {-access }}+T_{j \text {-vehicle }}
$$

where $T_{i j \text {-access }}$ is the network-based travel time from original community $i$ to a URT station $j$ (access time); this study improves the conventional TOD and adopts extended TOD that assumes that URT catchment areas can be accessed by walk, bike, and feeder bus services. $T_{j \text {-vehicle }}$ is the travel time from a URT station $j$ to the city center (in-vehicle time).

$A_{j}$ is the attractiveness of a UTR station $j$. This study uses the additive form based on multicriteria decision analysis to incorporate the experts' opinions on the importance of factors that affect station choices. The attractiveness of a URT station was measured using three variables: Walk Score (WS), Public Transport Accessibility Level (PTAL), and Service Quality Index (SQI). Therefore, the calculation method of $A_{j}$ is shown as follows:

$$
A_{j}=\sum_{k=1}^{3} \mu_{k} m_{k}=\mu_{1} \cdot \mathrm{WS}+\mu_{2} \cdot \mathrm{PTAL}+\mu_{3} \cdot \mathrm{SQI},
$$

where $m_{k}$ is the factor $k$ that affects the URT station's attractiveness. $\mu_{n}$ is the weight of the factor, which is determined by experts through ranking the importance from 1 to 7 and using a 7-point Likert scale method. The method is a psychometric scale commonly involved in research used to represent people's opinions and attitudes to a topic or subject matter. It employs questionnaires, often used interchangeably with a rating scale (1 point: strongly unimportant; 2 points: unimportant; 3 points: somewhat unimportant; 4 points: neither important nor unimportant; 5 points: somewhat important; agree: 6 points: important; 7 points: strongly important).

(i) Walk Score (WS). Considering the difficulty of measuring land-use diversity directly, this study searches for another parameter to represent it. WS measures the built environment's ability to support walking for a given location. It combines information about the distance to the destination and the characteristics of the streets around the route [40]. WS is calculated based on the distance to 13 categories of amenities, each category is weighted equally, and scores are summed and then normalized to yield a score of $0-100$ [41]. Therefore, WS can also be employed to access land-use diversity due to the fact that it serves as a good proxy.

(ii) Public Transport Accessibility Level (PTAL). PTAL is the degree of convenience of residents who travel by public transport modes from origins to destinations. The commonly used methods to measure accessibility include infrastructure- [42], activity- [43], and utility-based accessibility models [44]. These models are not used in this study for several reasons. First, they have too many limitations in terms of data collection. Second, they require advanced mathematical methods and programming, which is difficult to solve practical problems [45]. Considering that the distribution of departure locations of commuters is random, it becomes more difficult to quantify the distance and time index to calculate the PTAL of URT station catchment areas. The arrival frequency of public transport reflects the convenience of commuters to stations and can be used to represent PTAL. In this study, the total elapsed time 
includes walking time to stations and average waiting time at stations. The walking time to stations is regarded as part of the average waiting time (i.e., public transport services are available at the "entrances" of stations, and commuters take public transport at the "entrances"). This study considers that the total elapsed time is equivalent to the departure interval, which can be characterized by the equivalent doorstep frequency (EDF) of public transport. A higher EDF indicates a higher PTAL, and the calculation of PTAL can be converted into calculation of EDF. Therefore, this study adopts a simplified PTAL model to measure accessibility and proposes the following assumptions: (1) PTAL is equivalent to the accessibility level of all public transport modes. (2) The average waiting time is $1 / 2$ of the operating time between adjacent public transport stations. (3) The interference factor is inversely proportional to the arrival rate of public transport, which is only related to public transport modes. Therefore, PTAL could be calculated as follows:

$$
\begin{aligned}
\mathrm{PTAL}^{*} & =\sum_{i=1}^{I} \frac{60}{t_{x i}+t_{y i}}, \\
\mathrm{PTAL} & =\sum \mathrm{PTAL}^{*}, \\
t_{x i} & =\frac{l_{i}}{v_{m}}, \\
t_{y i} & =\frac{1}{2} \times \frac{60}{r} \times K,
\end{aligned}
$$

where $\mathrm{PTAL}^{*}$ is the accessibility level of a specific public transport mode. PTAL is Public Transport Accessibility Level. $t_{x i}$ is the walking time of the $i^{\text {th }}$ path (min). $t_{y i}$ is the average waiting time of the $i^{\text {th }}$ path (min). $I$ is a set of routes between the entrances of communities and public transport stops. $l_{i}$ is the walking distance of the $i^{\text {th }}$ path (m). $v_{m}$ is the average walking speed $(\mathrm{m} / \mathrm{min}) . K$ is the interference factor, which can be obtained from surveys and assigned a value of 1 2. $r$ is the arrival rate of public transport (veh/h).

(iii) Service Quality Index (SQI). The service quality of a URT station includes two aspects: service frequency and service facilities. The service frequency is the frequency of train arrivals at each station, which can be calculated by using the data of the average number of trains that serve a URT station every hour. The service facilities index includes 10 types of facilities (bikesharing parking spaces, elevators, waiting area, chairs, toilets, disabled facilities, vending machines, ATM change machines, convenience store, and office personnel), which can be calculated using a 7-point Likert scale method. Based on the existing study conducted by Chen et al. [30], the frequency is twice more important as facilities; then SQI can be calculated as follows:

$$
\mathrm{SQI}=f_{j}+0.5 \times \frac{\sum_{m=1}^{n_{j}} \sum_{n=1}^{10} q_{j m n}}{10 n_{j}},
$$

where SQI is the Service Quality Index. $f$ is the service frequency of station $j . q_{j m n}$ is the value of facility $n$ evaluated by participant $m . n_{j}$ is the number of participants who evaluate facility $n$ at station $j$.

Due to the fact that all these factors are measured in different units, we standardized them into one attractiveness index using the score range method [46], which can be shown as follows:

$$
S_{i j}^{\prime}=\frac{S_{i j}-S_{j}^{\min }}{S_{j}^{\max }-S_{j}^{\min }},
$$

where $S_{i j}^{\prime}$ represents the standardized value for item $i$ in $j^{\text {th }}$ factor. $S_{i j}^{\min }$ represents the minimum value for the $j^{\text {th }}$ factor. $S_{i j}^{\max }$ represents the maximum value for the $j^{\text {th }}$ factor. $S_{i j}^{\max }-S_{i j}^{\min }$ represents the range of given criteria.

3.3. Linear Referencing Method. The linear referencing method is used to define the spatial boundary of URT station catchment areas. The improved Huff model calculates the probabilities of a URT station being selected from a particular location, such as a centroid of a community. Residents in a community can choose multiple $(j \geq 2)$ URT stations with different probabilities. The underlying principle is that the probability of choosing a URT station is inversely proportional to the distance between a community and a station. The process of this method can be depicted: if the probability of a URT station being chosen is lower, the centroid of a community will be moved away from its original location and get closer to the station. The lower the probability $P_{i j}$, the more the adjustment of the centroid of a community $i$ and the shorter the distance $d_{i j}^{\prime}$. Therefore, it could be calculated as follows:

$$
d_{i j}^{\prime}=d_{i j} \cdot\left(1-\frac{P_{i j}}{P_{i j}^{\max }}\right),
$$

where $d_{i j}^{\prime}$ is the adjusted distance from the centroid of a community $i$ to station $j$, which determines the calibrated origin. $d_{i j}$ is the distance from the centroid of a community $i$ to station $j . P_{i j}$ is the probability of choosing station $j$ from the centroid of a community $i$ to the central urban area. $p_{i j}^{\max }$ is the maximum probability of a station being chosen from the centroid of a community $i$ to the city center.

As each calibrated origin point represents a community, the spatial boundary of a URT station is drawn by selecting the intersected communities of a station and dissolving or aggregating the boundary of the selected community's polygons into one area of the station using the ArcGIS ${ }^{\mathrm{TM}}$ software. The process of how to determine the boundaries using Model Builder ${ }^{\mathrm{TM}}$ in the ArcGIS software is shown in Figure 1. 


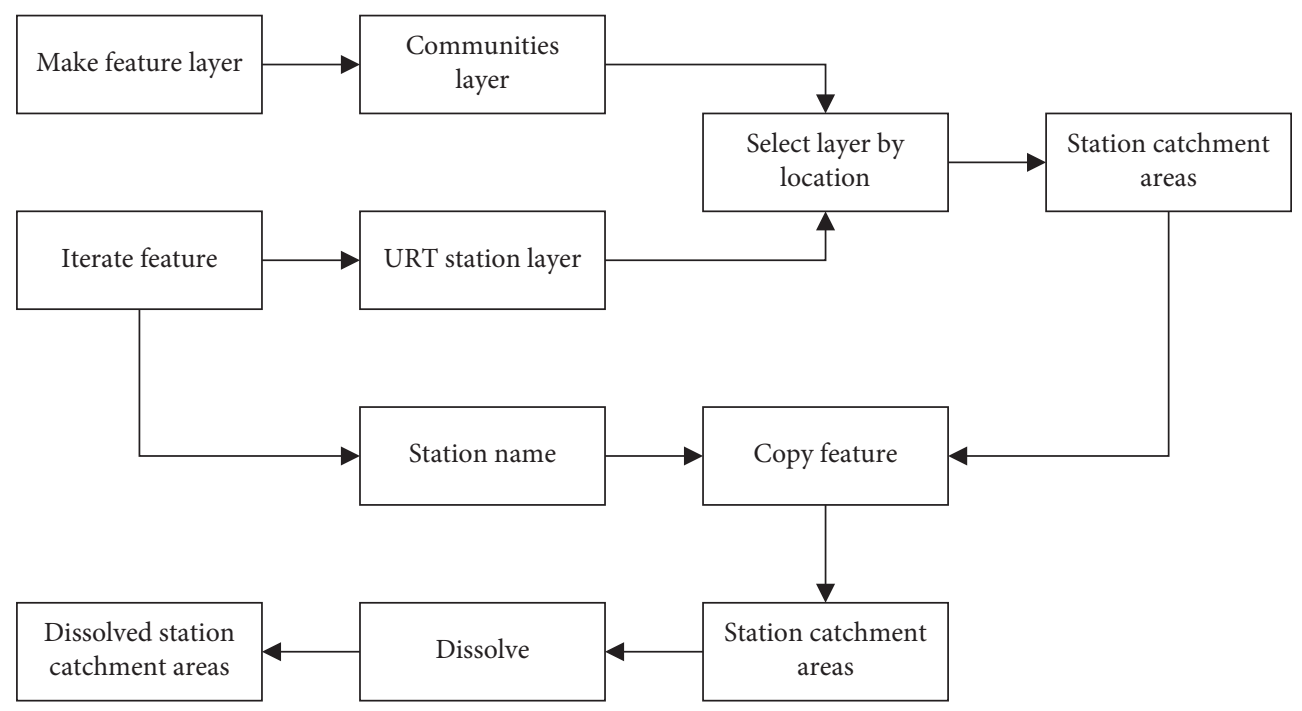

Figure 1: Process of determining the boundaries.

\section{Case Study}

4.1. Data. Xi'an, located in Northwest China, is a key city in China. By the end of 2017, Xi'an had a total population of 9.05 million, ranked the 23rd in China. The urban built area in Xi' an is $683.09 \mathrm{~km}^{2}$; private car ownership increased rapidly in Xi'an with an average yearly increase rate of $11 \%$ between 2010 and 2017. By the end of 2017, the city of Xi'an had 2.46 million private cars and 3.7 million registered car drivers [47]. The growth in auto ownership and use has led to traffic congestion; accordingly, URT is built to reduce auto use and mitigate congestion. Xi'an plans to construct 17 URT lines by 2030, and now three URT lines are in operation, $91 \mathrm{~km}$ long, and have 63 stations (see Table 1; Figure 2). Line 1 runs from east to west. Opened in 2013, the line is $25.4 \mathrm{~km}$ long and has 19 stations. Line 2 was fully opened in 2014, runs from north to south, is $26.8 \mathrm{~km}$ long, and has 21 stations. Line 3 was fully opened in 2016, runs from northeast to west, is $39.15 \mathrm{~km}$ long, and has 26 stations. This study simplifies the analysis considering all trips to the Zhonglou area (the area enclosed by Xi'an Circumvallation), which is the largest employment center and largest destination in Xi'an.

The study used multiple sources collected from two sources: a field survey and archival data from related government departments. To understand residents' station choice behavior, intercept surveys were conducted to collect travel data of all public transport users and their satisfaction with URT services and facilities. This study randomly chose URT users at station platforms and asked them to fill in the questionnaire. In order to determine the weight of factors that affect the attractiveness of UTR stations, experts from universities, research institutions, and transportation planning bureau are interviewed. Public transport timetable information is obtained from the Department of Planning, Department of Transportation.

4.2. Results. Based on experts' opinions on the importance of factors that affect station choices, using the 7-point Likert scale method, the weight of WS, PTAL, and SQI is obtained, respectively, $\mu 1=0.41, \mu 1=0.32$, and $\mu 1=0.27$. According to formula (2) formula (6), the standardized value of WS, PTAL, and SQI of each URT station can be calculated (see Table 2). According to the proposed methodology and data set, we obtain the station attractiveness index of each station in Xi'an, China (see Figure 3). The index indicates that stations of downtown areas have higher attractiveness, while that of suburbs have lower attractiveness. In addition, we see that three stations: $\mathrm{M}_{12}$ (Nanshaomen), $\mathrm{M}_{13}$ (Tiyuchang), and $\mathrm{M}_{14}$ (Xiaozhai) that do not locate in downtown areas have the most higher attractiveness because the Xiaozhai area is not only the important business center of Xi'an within good walkability but also the transport interchange hub within good accessibility. Although URT stations, such as $\mathrm{L}_{8}$ (Yuxiangmen), L9 (Sajinqiao), and $\mathrm{L}_{12}$ (Chaoyangmen) that locate in or adjacent to the Xi'an Circumvallation, were used to be historic downtown of Xi'an, they have lower attractiveness due to the fact that the existing road network is dominated by Li-Fang Unit system, and the demand for historic downtown protection resulted in limited transportation facility supply.

Stations of downtown areas have higher attractiveness, while that of suburbs have lower attractiveness. This may be due to the better pedestrian system and bus coverage in the central city. On the one hand, this increases the accessibility of the stations. On the other hand, the rail stations in the central city have better facilities and better service quality compared to suburban stations. For a long time, suburban areas have been built with the extreme pursuit of wide roads and less attention to slow transportation (pedestrian system, bicycle sharing, etc.), resulting in lower accessibility. Suburban transit ridership is low. For profit purposes, bus systems in the suburbs are less frequent and suffer from inadequate service facilities and low service quality. The coupling between public transportation and land use is rarely considered in suburban development and construction. For example, a large number of new residential areas have been built in the suburbs, which lengthens the operating mileage of public transportation. The combined 
TABLE 1: Coding for urban rail transit stations in Xi'an, China.

\begin{tabular}{|c|c|c|c|c|c|}
\hline Code & Station name & Code & Station name & Code & Station name \\
\hline $\mathrm{L}_{1}$ & Houweizhai & $\mathrm{M}_{3}$ & Yundonggongyuan & $\mathrm{R}_{4}$ & Kejilu \\
\hline $\mathrm{L}_{2}$ & Sanqiao & $\mathrm{M}_{4}$ & Xingzhengzhongxin & $\mathrm{R}_{5}$ & Taibainanlu \\
\hline $\mathrm{L}_{3}$ & Zaohe & $\mathrm{M}_{5}$ & Fengchengwulu & $\mathrm{R}_{6}$ & Jixiangcun \\
\hline $\mathrm{L}_{4}$ & Zhaoyuan & $\mathrm{M}_{6}$ & Shitushuguan & $\mathrm{R}_{7}$ & Dayanta \\
\hline $\mathrm{L}_{5}$ & Hanchenglu & $\mathrm{M}_{7}$ & Daminggongxi & $\mathrm{R}_{8}$ & Beichitou \\
\hline $\mathrm{L}_{6}$ & Kaiyuanmen & $\mathrm{M}_{8}$ & Longshouyuan & $\mathrm{R}_{9}$ & Qinglongshi \\
\hline $\mathrm{L}_{7}$ & Laodonglu & $\mathrm{M}_{9}$ & Anyuanmen & $\mathrm{R}_{10}$ & Yanxingmen \\
\hline $\mathrm{L}_{8}$ & Yuxiangmen & $\mathrm{M}_{10}$ & Zhonglou & $\mathrm{R}_{11}$ & Xianningmen \\
\hline $\mathrm{L}_{9}$ & Sajinqiao & $\mathrm{M}_{11}$ & Yongningmen & $\mathrm{R}_{12}$ & Changle park \\
\hline $\mathrm{L}_{10}$ & Beidajie & $\mathrm{M}_{12}$ & Nanshaomen & $\mathrm{R}_{13}$ & Hujiamiao \\
\hline $\mathrm{L}_{11}$ & Wulukou & $\mathrm{M}_{13}$ & Tiyuchang & $\mathrm{R}_{14}$ & Shijiajie \\
\hline $\mathrm{L}_{12}$ & Chaoyangmen & $\mathrm{M}_{14}$ & Xiaozhai & $\mathrm{R}_{15}$ & Xinjiamiao \\
\hline $\mathrm{L}_{13}$ & Kangfulu & $\mathrm{M}_{15}$ & Weiyijie & $\mathrm{R}_{16}$ & Guangtaimen \\
\hline $\mathrm{L}_{14}$ & Tonghuamen & $\mathrm{M}_{16}$ & Huizhanzhongxin & $\mathrm{R}_{17}$ & Taohuatan \\
\hline $\mathrm{L}_{15}$ & Wanshoulu & $\mathrm{M}_{17}$ & Sanyao & $\mathrm{R}_{18}$ & Chanbazhongxin \\
\hline $\mathrm{L}_{16}$ & Changlepo & $\mathrm{M}_{18}$ & Fengqiyuan & $\mathrm{R}_{19}$ & Xianghuwan \\
\hline $\mathrm{L}_{17}$ & Chanhe & $\mathrm{M}_{19}$ & Hangtiancheng & $\mathrm{R}_{20}$ & Wuzhuang \\
\hline $\mathrm{L}_{18}$ & Banpo & $\mathrm{M}_{20}$ & Weiqunan & $\mathrm{R}_{21}$ & Guojigangwuqu \\
\hline $\mathrm{L}_{19}$ & Fangzhicheng & $\mathrm{R}_{1}$ & Yuhuazhai & $\mathrm{R}_{22}$ & Shuangzhai \\
\hline $\mathrm{M}_{1}$ & Xi'anbei & $\mathrm{R}_{2}$ & Zhangbabeilu & $\mathrm{R}_{23}$ & Xinzhu \\
\hline $\mathrm{M}_{2}$ & Bieyuan & $\mathrm{R}_{3}$ & Yanpingmen & $\mathrm{R}_{24}$ & Baoshuiqu \\
\hline
\end{tabular}

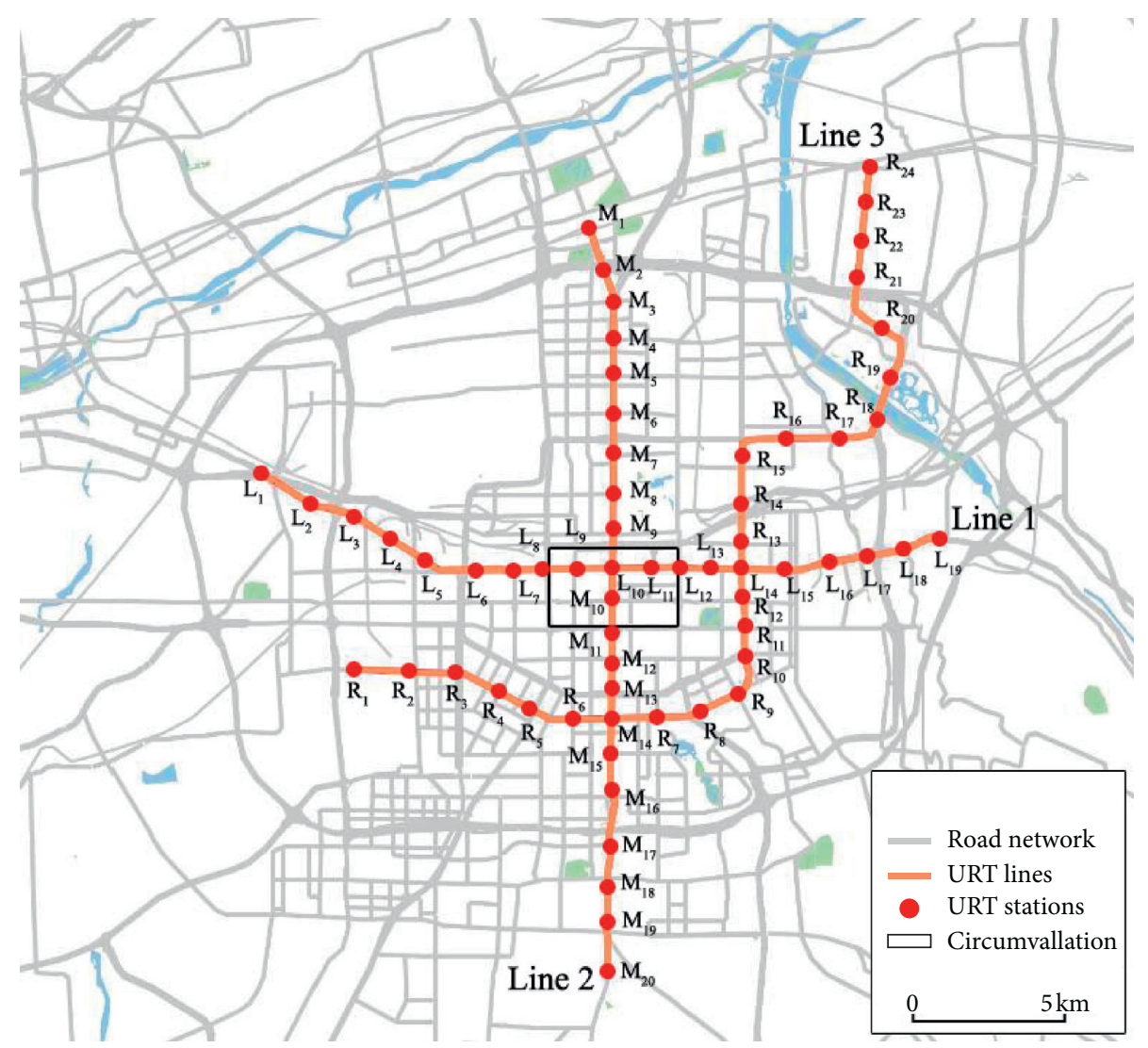

Figure 2: Urban rail transit network of Xi'an, China.

effect of long operating mileage and low frequency of departures reduces the accessibility of public transportation. The construction of public transportation facilities can effectively improve the attractiveness of the station, for example, Fangzhicheng Station. Compared with other suburban stations, the Fangzhicheng Station site attractiveness is high. This is inseparable from the construction of the surrounding Fangzhicheng bus station. Through the site attractiveness classification site, it is beneficial to put forward targeted development strategies according to various types of sites. For the highly 
TABLE 2: The calculated variables of models.

\begin{tabular}{|c|c|c|c|c|c|c|c|c|c|c|c|c|c|c|}
\hline Code & WS & PTAL & SQI & $\mathrm{Aj}$ & Code & WS & PTAL & SQI & $\mathrm{Aj}$ & Code & WS & PTAL & SQI & $\mathrm{Aj}$ \\
\hline $\mathrm{L}_{1}$ & 0.258 & 0.298 & 0.034 & 0.210 & $\mathrm{M}_{3}$ & 0.529 & 0.455 & 0.398 & 0.470 & $\mathrm{R}_{4}$ & 0.588 & 0.527 & 0.630 & 0.580 \\
\hline $\mathrm{L}_{2}$ & 0.331 & 0.252 & 0.023 & 0.223 & $\mathrm{M}_{4}$ & 0.552 & 0.444 & 0.427 & 0.484 & $\mathrm{R}_{5}$ & 0.609 & 0.518 & 0.607 & 0.579 \\
\hline $\mathrm{L}_{3}$ & 0.469 & 0.405 & 0.052 & 0.336 & $\mathrm{M}_{5}$ & 0.583 & 0.438 & 0.920 & 0.628 & $\mathrm{R}_{6}$ & 0.573 & 0.463 & 0.584 & 0.541 \\
\hline $\mathrm{L}_{4}$ & 0.341 & 0.301 & 0.069 & 0.255 & $\mathrm{M}_{6}$ & 0.558 & 0.413 & 0.948 & 0.617 & $\mathrm{R}_{7}$ & 0.783 & 0.641 & 0.641 & 0.699 \\
\hline $\mathrm{L}_{5}$ & 0.361 & 0.302 & 0.086 & 0.268 & $\mathrm{M}_{7}$ & 0.561 & 0.501 & 0.908 & 0.636 & $\mathrm{R}_{8}$ & 0.721 & 0.538 & 0.607 & 0.632 \\
\hline $\mathrm{L}_{6}$ & 0.678 & 0.628 & 0.109 & 0.508 & $\mathrm{M}_{8}$ & 0.571 & 0.663 & 0.885 & 0.685 & $\mathrm{R}_{9}$ & 0.674 & 0.526 & 0.578 & 0.601 \\
\hline $\mathrm{L}_{7}$ & 0.724 & 0.649 & 0.092 & 0.529 & $\mathrm{M}_{9}$ & 0.641 & 0.608 & 0.954 & 0.715 & $\mathrm{R}_{10}$ & 0.622 & 0.487 & 0.601 & 0.573 \\
\hline $\mathrm{L}_{8}$ & 0.765 & 0.413 & 0.040 & 0.457 & $\mathrm{M}_{10}$ & 0.886 & 0.419 & 0.937 & 0.750 & $\mathrm{R}_{11}$ & 0.636 & 0.521 & 0.612 & 0.593 \\
\hline $\mathrm{L}_{9}$ & 0.806 & 0.361 & 0.126 & 0.480 & $\mathrm{M}_{11}$ & 0.746 & 0.453 & 0.983 & 0.716 & $\mathrm{R}_{12}$ & 0.654 & 0.548 & 0.624 & 0.612 \\
\hline $\mathrm{L}_{10}$ & 0.834 & 0.422 & 0.166 & 0.522 & $\mathrm{M}_{12}$ & 0.759 & 0.618 & 0.937 & 0.762 & $\mathrm{R}_{13}$ & 0.636 & 0.546 & 0.549 & 0.584 \\
\hline $\mathrm{L}_{11}$ & 0.816 & 0.452 & 0.161 & 0.523 & $\mathrm{M}_{13}$ & 0.783 & 0.668 & 0.977 & 0.799 & $\mathrm{R}_{14}$ & 0.586 & 0.481 & 0.555 & 0.544 \\
\hline $\mathrm{L}_{12}$ & 0.715 & 0.418 & 0.143 & 0.466 & $\mathrm{M}_{14}$ & 0.824 & 0.753 & 1.000 & 0.849 & $\mathrm{R}_{15}$ & 0.543 & 0.638 & 0.567 & 0.580 \\
\hline $\mathrm{L}_{13}$ & 0.733 & 0.621 & 0.097 & 0.526 & $\mathrm{M}_{15}$ & 0.729 & 0.593 & 0.937 & 0.742 & $\mathrm{R}_{16}$ & 0.421 & 0.391 & 0.584 & 0.455 \\
\hline $\mathrm{L}_{14}$ & 0.767 & 0.798 & 0.080 & 0.592 & $\mathrm{M}_{16}$ & 0.696 & 0.571 & 0.954 & 0.726 & $\mathrm{R}_{17}$ & 0.383 & 0.316 & 0.572 & 0.413 \\
\hline $\mathrm{L}_{15}$ & 0.638 & 0.709 & 0.115 & 0.519 & $\mathrm{M}_{17}$ & 0.621 & 0.534 & 0.903 & 0.669 & $\mathrm{R}_{18}$ & 0.184 & 0.161 & 0.589 & 0.286 \\
\hline $\mathrm{L}_{16}$ & 0.619 & 0.583 & 0.097 & 0.467 & $\mathrm{M}_{18}$ & 0.489 & 0.518 & 0.828 & 0.590 & $\mathrm{R}_{19}$ & 0.132 & 0.153 & 0.291 & 0.182 \\
\hline $\mathrm{L}_{17}$ & 0.512 & 0.418 & 0.000 & 0.344 & $\mathrm{M}_{19}$ & 0.449 & 0.319 & 0.794 & 0.500 & $\mathrm{R}_{20}$ & 0.159 & 0.089 & 0.561 & 0.245 \\
\hline $\mathrm{L}_{18}$ & 0.453 & 0.571 & 0.075 & 0.389 & $\mathrm{M}_{20}$ & 0.331 & 0.382 & 0.868 & 0.492 & $\mathrm{R}_{21}$ & 0.198 & 0.122 & 0.589 & 0.279 \\
\hline $\mathrm{L}_{19}$ & 0.533 & 0.489 & 0.109 & 0.404 & $\mathrm{R}_{1}$ & 0.158 & 0.184 & 0.544 & 0.270 & $\mathrm{R}_{22}$ & 0.084 & 0.062 & 0.578 & 0.210 \\
\hline $\mathrm{M}_{1}$ & 0.442 & 0.512 & 0.421 & 0.459 & $\mathrm{R}_{2}$ & 0.403 & 0.427 & 0.561 & 0.453 & $\mathrm{R}_{23}$ & 0.071 & 0.108 & 0.549 & 0.212 \\
\hline $\mathrm{M}_{2}$ & 0.502 & 0.447 & 0.364 & 0.447 & $\mathrm{R}_{3}$ & 0.528 & 0.593 & 0.612 & 0.572 & $\mathrm{R}_{24}$ & 0.038 & 0.073 & 0.532 & 0.183 \\
\hline
\end{tabular}

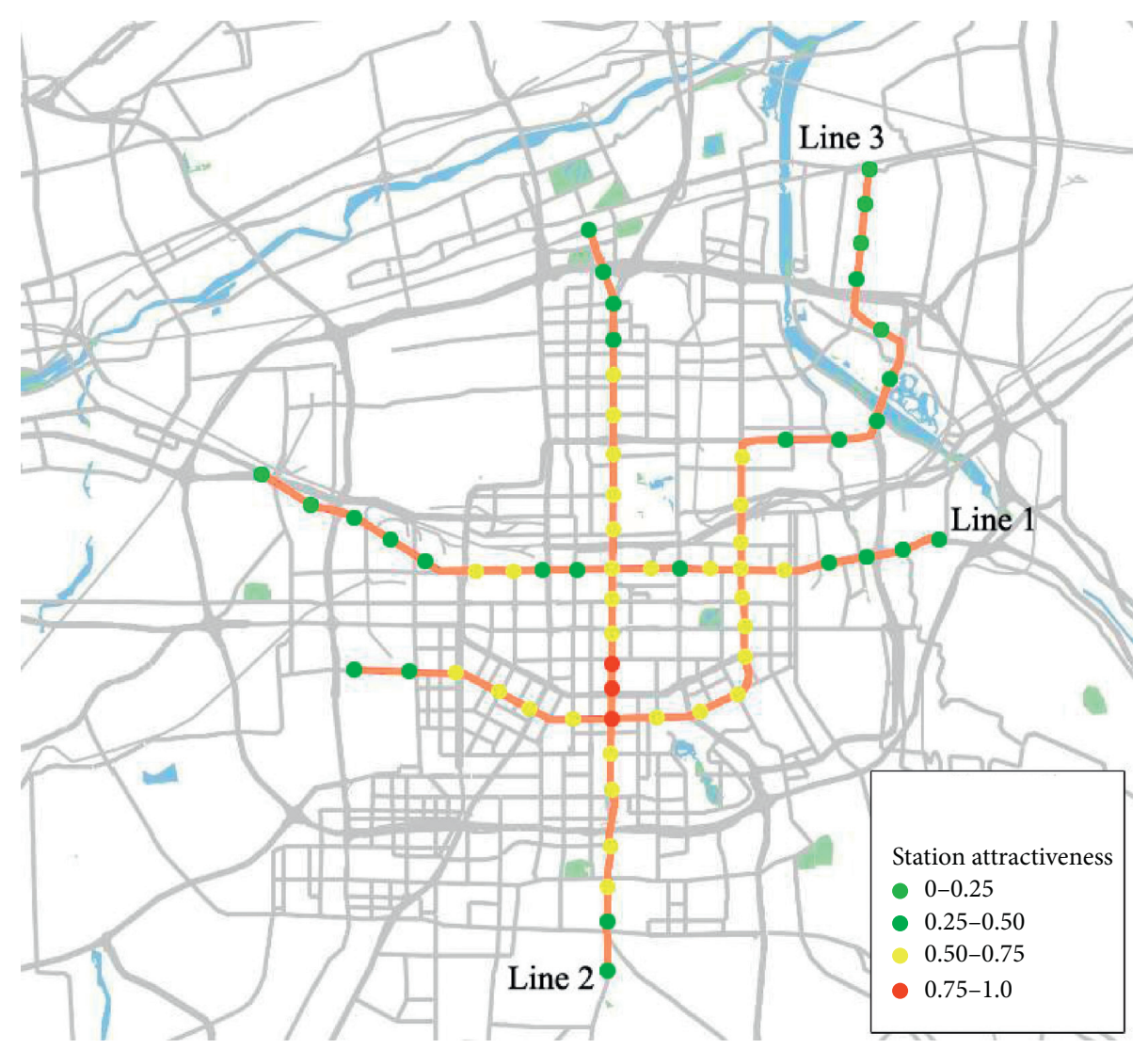

Figure 3: Calculated station attractiveness of urban rail transit.

attractive stations $\left(\mathrm{R}_{18}-\mathrm{R}_{24}\right)$, it is recommended that parking allocation standards be appropriately reduced to regulate small car trips. Reduce the pressure of motor vehicle trips on the transportation system, while improving the level of public transport provision and the pedestrian environment. For low attractiveness sites (most of the suburban sites), the level of public transportation supply can be supplemented by increasing the frequency of bus stops and departures. This will 


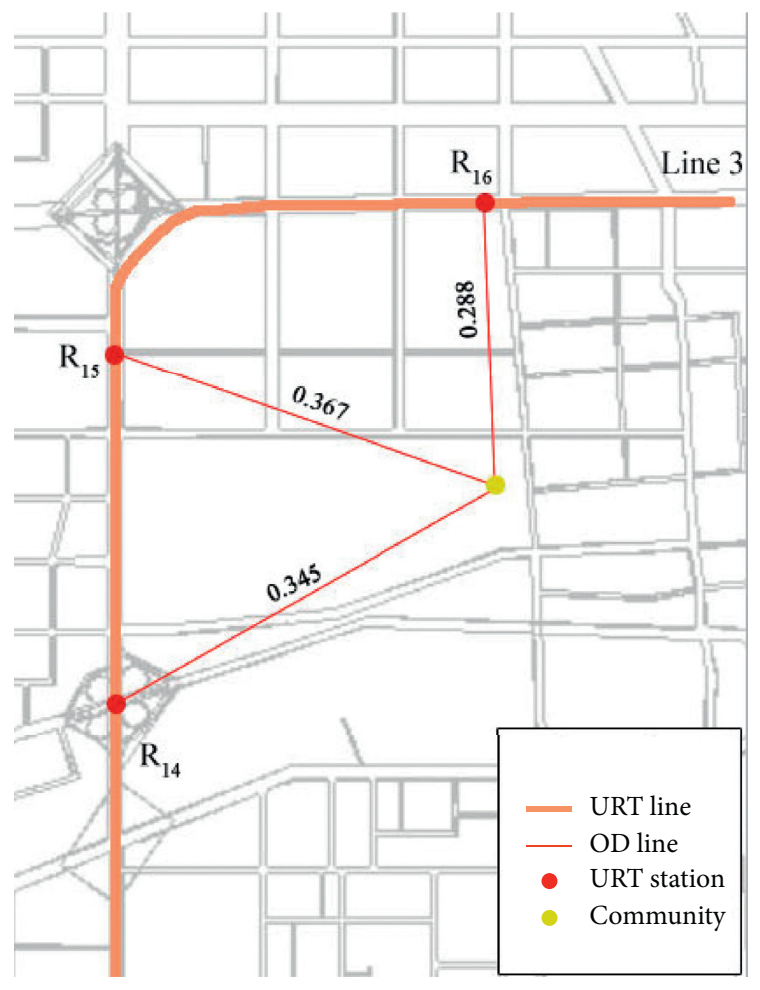

(a)

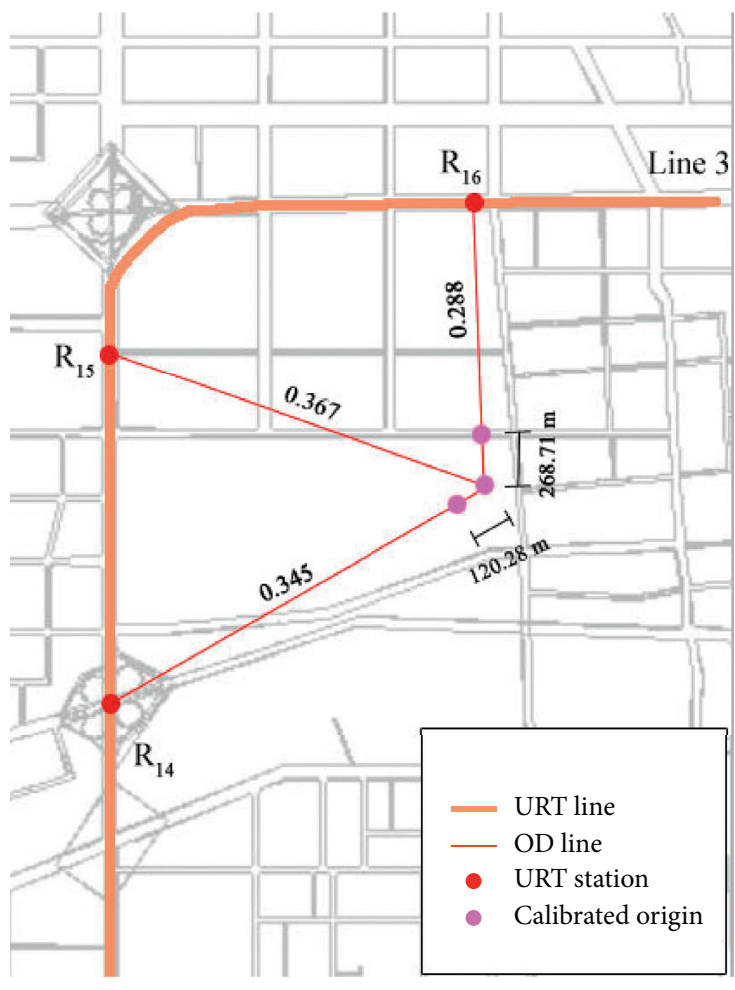

(b)

FIgURE 4: Outputs from the improved Huff model and origin calibration.

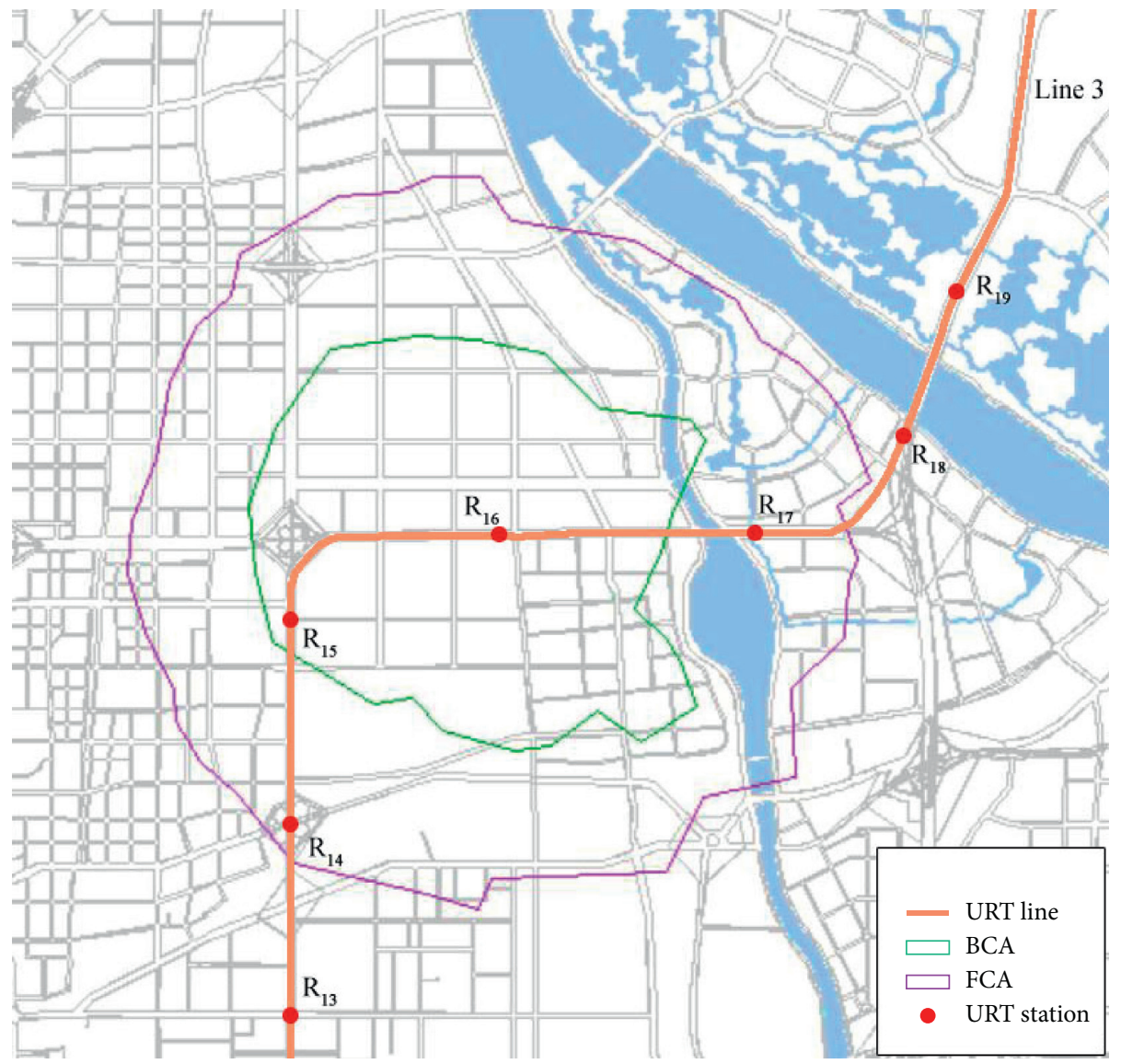

Figure 5: Catchment areas of Guangtaimen station. 
increase the attractiveness of rail transit stations. Also, slow traffic facilities around the stations can be complemented to plan for future development.

Figures 4(a) and 4(b) provide an example of outputs from the improved Huff model to elaborate how the method was applied. This study defines that three stations will be chosen by residents from Dongfangluoma Community which are $\mathrm{R}_{14}$ (Shijiajie), $\mathrm{R}_{15}$ (Xinjiamiao), and $R_{16}$ (Guangtaimen). The probabilities of the three stations being chosen are $0.345,0.367$, and 0.288 .

Each calibrated origin represents a community; Model Builder in the ArcGIS software is used to obtain spatial boundaries of a URT station $\mathrm{R}_{16}$ (Guangtaimen) by selecting the intersected communities and dissolving or aggregating the boundary of selected communities' polygons into one area. Finally, two spatial boundaries are obtained within cycling and feeder bus services, corresponding to bicycle-oriented catchment areas (BCA) and feeder bus-oriented catchment areas (FCA) (see Figure 5).

\section{Conclusions}

Estimating URT station catchment areas will help to allocate public transport facilities to promote transit-oriented development, which is of great significance to cities with high density. This study focused on the station choice of developing countries' URT and integrated the walking, cycling, and feeder bus based on the TOD framework. What is more, this study proposed a new methodology based on the improved Huff model to determine URT station catchment areas, which considers the attractiveness of stations from the aspects of walk score, public transport accessibility level, and service quality index. This study used Xi'an, China, as a case study to validate the applicability of the proposed methodology. The results revealed that when URT lines develop into network, residents would have multiple station choices that depended on the station attractiveness; thus, station catchment areas are further extended.

However, there still exist some limitations in the present study. First, some parameter calibration directly used the existing accepted value, which could not reflect the improved Huff model better. Therefore, the distance decay parameter will be calibrated to investigate the impact of spatial variation in future studies. Some more parameters such as traffic congestion should be also considered. Second, many other factors such as the level of service coverage or network connectivity of a URT station, the function position of the station in the network, being close to important destination stations in the network, and travel costs have a significant impact on the service quality of a URT station, which do not take into consideration in the study. Also, the in-depth consideration of transit frequency should be made in future studies, within the available related big data, the transit frequency can be modeled [45]. Therefore, a new approach that integrates all these aspects is recommended to measure the service quality of a URT station. Third, this study used the centroid location communities as a substitution, which reduced the accuracy of geocoding.
Despite these limitations, this study developed a new approach based on the improved Huff model to estimate URT station catchment areas. It will be of importance to public transit policymakers, city planners, and researchers, particularly the public transport authority, to understand station choice behaviors, therefore make adjustments of travel fees, and improve the service quality of URT stations and to allocate public transport facilities reasonably around station catchment areas to meet residents' travel demand. The major contribution of this study is the development of the Huff model for identifying variables affecting station choice. The method is reproducible and generalizable internationally to other studies.

\section{Data Availability}

The data used in this study can be obtained upon request to the corresponding author.

\section{Conflicts of Interest}

The authors declare no conflicts of interest.

\section{Acknowledgments}

This work was supported by the Scientific Research Foundation for Advanced Talents of Nanjing Forestry University (no. 163106041), the General Project of Philosophy and Social Science Foundation of the Jiangsu Higher Education Institutions of China (2020SJA0125), and the General Program of the Natural Science Foundation of the Jiangsu Higher Education Institutions of China (20KJB580013).

\section{References}

[1] Ö. Özgür-Cevher, O. Altintasi, and H. Tuydes-Yaman, "Evaluating the relation between station area design parameters and transit usage for urban rail systems in Ankara, Turkey," International Journal of Civil Engineering, vol. 18, no. 8, pp. 951-966, 2020.

[2] S. Bhattacharjee and A. R. Goetz, "Impact of light rail on traffic congestion in Denver," Journal of Transport Geography, vol. 22, pp. 262-270, 2012.

[3] D. V. Batsos and J. Tzouvadakis, "New metro system as a catalyst for successful planning interventions in athens," Journal of Urban Planning and Development, vol. 137, no. 1, pp. 49-55, 2011.

[4] The Light Rail Transit Association, Web Document, http:// www.lrta.org/world/worldind.htm\#index, 2018.

[5] Ministry of transport of the people's Republic of China. Statistical Bulletin of Transportation Industry Development, 2018.

[6] D. B. Hess and T. M. Almeida, "Impact of proximity to light rail rapid transit on station-area property values in Buffalo, New York," Urban Studies, vol. 44, no. 5-6, pp. 1041-1068, 2007.

[7] A. El-Geneidy, M. Grimsrud, R. Wasfi, P. Tétreault, and J. Surprenant-Legault, "New evidence on walking distances to transit stops: identifying redundancies and gaps using variable service areas," Transportation, vol. 41, no. 1, pp. 193-210, 2014.

[8] B. B. Brown and C. M. Werner, "Before and after a new light rail stop: resident attitudes, travel behavior, and obesity," 
Journal of the American Planning Association, vol. 75, no. 1, pp. 5-12, 2008.

[9] G. Pivo and J. D. Fisher, "The walkability premium in commercial real estate investments," Real Estate Economics, vol. 39, no. 2, pp. 185-219, 2011.

[10] D. R. Loutzenheiser, "Pedestrian access to transit: model of walk trips and their design and urban form determinants around bay area rapid transit stations," Transportation Research Record: Journal of the Transportation Research Board, vol. 1604, no. 1, pp. 40-49, 1997.

[11] G. Debrezion, E. Pels, and P. Rietveld, "Modelling the joint access mode and railway station choice," Transportation Research Part E: Logistics and Transportation Review, vol. 45, pp. 270-283, 2007.

[12] S. Ann, M. Jiang, and T. Yamamoto, "Influence area of transitoriented development for individual Delhi metro stations considering multimodal accessibility," Sustainability, vol. 11, pp. 1-23, 2019.

[13] C. Upchurch, M. Kuby, M. Zoldak, and A. Barranda, "Using GIS to generate mutually exclusive service areas linking travel on and off a network," Journal of Transport Geography, vol. 12, no. 1, pp. 23-33, 2004.

[14] M. Kuby, A. Barranda, and C. Upchurch, "Factors influencing light-rail station boardings in the United States," Transportation Research Part A: Policy and Practice, vol. 38, no. 3, pp. 223-247, 2004.

[15] A. M. El-Geneidy, P. Tetreault, and J. Surprenant-Legault, "Pedestrian access to transit: identifying redundancies and gaps using a variable service area analysis," in Proceedings of the Transportation Research Board 89th Annual Meeting, Washington, DC, USA, 2010.

[16] H. Zhao, X. Yan, and Z. Gao, "Transportation serviceability analysis for metropolitan commuting corridors based on modal choice modeling," Transportation Research Part A: Policy and Practice, vol. 49, pp. 270-284, 2013.

[17] C. Liu, S. Erdogan, T. Ma et al., "How to increase rail ridership in Maryland? Direct ridership models (DRM) for policy guidance," Journal of Urban Planning and Development, vol. 142, 2014.

[18] S. O'Sullivan and J. Morrall, "Walking distances to and from light-rail transit stations," Transportation Research Record: Journal of the Transportation Research Board, vol. 1538, no. 1, pp. 19-26, 1996.

[19] G. A. Malavenda, G. Musolino, C. Rindone, and A. Vitetta, "Residential location, mobility, and travel time: a pilot study in a small-size Italian metropolitan area," Journal of Advanced Transportation, vol. 2020, Article ID 8827466, 11 pages, 2020.

[20] L. Dolega, M. Pavlis, and A. Singleton, "Estimating attractiveness, hierarchy and catchment area extents for a national set of retail centre agglomerations," Journal of Retailing and Consumer Services, vol. 28, pp. 78-90, 2016.

[21] Y. Wang, N. Zhao, X. Liu et al., "Identifying big five personality traits through controller area network bus data," Journal of Advanced Transportation, vol. 2020, Article ID 8866876, 11 pages, 2020.

[22] H. Hwang, S.-H. Cho, D.-K. Kim, and S.-Y. Kho, "Development of a model for evaluating the coverage area of transit center using smart card data," Journal of Advanced Transportation, vol. 2020, Article ID 8819791, 13 pages, 2020.

[23] A. Nuzzolo and A. Comi, "A subjective optimal strategy for transit simulation models," Journal of Advanced Transportation, vol. 2018, pp. 1-10, 2018.

[24] G. Musolino, C. Rindone, and A. Vitetta, "Evaluation in transport planning: a comparison between data envelopment analysis and multi criteria decision making methods," in Proceedings of the European Simulation and Modelling Conference, Lisbon, Portugal, 2017.

[25] D. L. Huff, "A probabilistic analysis of shopping center trade areas," Land Economics, vol. 39, no. 1, pp. 81-90, 1963.

[26] T. Lin, J. Xia, T. P. Robinson et al., "Enhanced huff model for estimating park and ride (PnR) catchment areas in Perth, WA," Journal of Transport Geography, vol. 54, pp. 336-348, 2016.

[27] C. R. Kastrenakes, "Development of a rail station choice model for NJ transit," Transportation Research Record, vol. 1162, pp. 16-21, 1988.

[28] D. A. Hensher, J. M. Rose, and W. H. Greene, Applied Choice Analysis, Camberidge University, Cambridge University Press, New York, NY, USA, 2005.

[29] R. Cervero, "Transit-oriented development's ridership bonus: a product of self-selection and public policies," Environment and Planning A: Economy and Space, vol. 39, no. 9, pp. 2068-2085, 2007.

[30] Z. Chen, J. Xia, B. Irawan, and C. Caulfied, "Development of location-based services for recommending departure stations to park and ride users," Transportation Research Part C: Emerging Technologies, vol. 48, pp. 256-268, 2014.

[31] C. Shao, J. C. Xia, T. G. Lin, K. G. Goulias, and C. Chen, "Logistic regression models for the nearest train station choice: a comparison of captive and non-captive stations," Case Studies on Transport Policy, vol. 3, no. 4, pp. 382-391, 2015.

[32] M. Ryan, T. Lin, J. Xia et al., "Comparison of perceived and measured accessibility between different age groups and travel modes at Greenwood Station, Perth, Australia," European Journal of Transport and Infrastructure Research, vol. 16, no. 2, pp. 406-423, 2016.

[33] M. Brons, M. Givoni, and P. Rietveld, "Access to railway stations and its potential in increasing rail use," Transportation Research Part A: Policy and Practice, vol. 43, no. 2, pp. 136-149, 2009.

[34] G. Debrezion, E. Pels, and P. Rietveld, "Choice of departure station by railway users," European Transport, vol. 37, pp. 78-92, 2007.

[35] G. Birgillito, C. Rindone, and A. Vitetta, "Passenger mobility in a discontinuous space: modelling access/egress to maritime barrier in a case study," Journal of Advanced Transportation, vol. 2018, no. 1, pp. 1-13, 2018.

[36] Z. Zhu, Z. li, H. Chen, Y. Liu, and J. Zeng, "Subjective wellbeing in China: how much does commuting matter?" Transportation, vol. 46, no. 4, pp. 1505-1524, 2019.

[37] A. Sevtsuk and R. Kalvo, "Patronage of urban commercial clusters: a network-based extension of the Huff model for balancing location and size," Environment and Planning $B$ Urban Analytics and City Science, vol. 45, no. 3, pp. 508-528, 2018.

[38] L. Joseph and M. Kuby, Gravity Modeling and its Impacts on Location Analysis, Foundations of Location Analysis, Springer, Berlin, Germany, 2011.

[39] M. Birkin, G. Clarke, and M. Clarke, "Refining and operationalizing entropy-maximizing models for business applications," Geographical Analysis, vol. 42, no. 4, pp. 422-445, 2010.

[40] J. A. Hirsch, K. A. Moore, K. R. Evenson, D. A. Rodriguez, and A. V. D. Roux, "Walk score and transit score and walking in the multi-ethnic study of atherosclerosis," American Journal of Preventive Medicine, vol. 45, no. 2, pp. 158-166, 2013. 
[41] L. J. Carr, S. I. Dunsiger, and B. H. Marcus, "Walk score as a global estimate of neighborhood walkability," American Journal of Preventive Medicine, vol. 39, no. 5, pp. 460-463, 2010.

[42] E. López, A. Monzón, E. Ortega, and S. Mancebo Quintana, "Assessment of cross-border spillover effects of national transport infrastructure plans: an accessibility approach," Transport Reviews, vol. 29, no. 4, pp. 515-536, 2009.

[43] R. Paleti, P. Vovsha, R. Picado et al., "Development of time varying accessibility measures: application to the activitybased model for southern California region," in Proceedings of the Transportation Research Board 94th Annual Meeting, Washington, DC, USA, 2015.

[44] G. Gulhan, H. Ceylan, M. Özuysal, and H. Ceylan, "Impact of utility-based accessibility measures on urban public transportation planning: a case study of Denizli, Turkey," Cities, vol. 32, pp. 102-112, 2013.

[45] A. Croce, G. Musolino, C. Rindone, and Vitetta, "Transport system models and big data: zoning and graph building with traditional surveys, FCD and GIS," ISPRS International Journal of Geo-Information, vol. 8, no. 4, p. 187, 2019.

[46] Z. Zhu, X. Guo, J. Zeng et al., "Determining parking requirements for high-rise buildings located in urban rail transit station catchment areas: a new methodology," in Proceedings of the 97th Annual Meeting of the Transportation Research Board, Washington, DC, USA, 2018.

[47] Xian Municipal Bureau Statistics, Xi'an Statistical Yearbook 2018, China Statistics Press, Beijing, China, 2018. 